\title{
Chemically induced enucleation of activated bovine oocytes: chromatin and microtubule organization and production of viable cytoplasts
}

\author{
Naiara Zoccal Saraiva ${ }^{1,2}$, Clara Slade Oliveira ${ }^{3}$, Cláudia Lima Verde Leal ${ }^{4}$, Marina Ragagnin de Lima ${ }^{2}$, \\ Maite Del Collado ${ }^{2,4}$, Roberta Vantini ${ }^{2}$, Fabio Morato Monteiro ${ }^{5}$, Simone Cristina Méo Niciura ${ }^{6}$ \\ and Joaquim Mansano Garcia ${ }^{2}$ \\ Embrapa Amazônia Oriental, Belém; Universidade Estadual Paulista, Jaboticabal; Embrapa Dairy Cattle, Valença; Faculdade \\ de Zootecnia e Engenharia de Alimentos, Universidade de São Paulo, Pirassununga; Instituto de Zootecnia, Sertãozinho; and \\ Embrapa Southeast Livestock, São Carlos, Brazil
}

Date submitted: 13.3.2013. Date revised: 1.7.2014. Date accepted: 18.8.2014

\section{Summary}

As the standard enucleation method in mammalian nuclear transfer is invasive and damaging to cytoplast spatial organization, alternative procedures have been developed over recent years. Among these techniques, chemically induced enucleation (IE) is especially interesting because it does not employ ultraviolet light and reduces the amount of cytoplasm eliminated during the procedure. The objective of this study was to optimize the culture conditions with demecolcine of pre-activated bovine oocytes for chemically IE, and to evaluate nuclear and microtubule organization in cytoplasts obtained by this technique and their viability. In the first experiment, a negative effect on oocyte activation was verified when demecolcine was added at the beginning of the process, reducing activation rates by approximately $30 \%$. This effect was not observed when demecolcine was added to the medium after $1.5 \mathrm{~h}$ of activation. In the second experiment, although a reduction in the number of microtubules was observed in most oocytes, these structures did not disappear completely during assessment. Approximately $50 \%$ of treated oocytes presented microtubule reduction at the end of the evaluation period, while $23 \%$ of oocytes were observed to exhibit the complete disappearance of these structures and $28 \%$ exhibited visible microtubules. These findings indicated the lack of immediate microtubule repolymerization after culture in demecolcine-free medium, a fact that may negatively influence embryonic development. However, cleavage rates of $63.6-70.0 \%$ and blastocyst yield of $15.5-24.2 \%$ were obtained in the final experiment, without significant differences between techniques, indicating that chemically induced enucleation produces normal embryos.

Keywords: Bovine, Chemically induced enucleation, Chromatin; Microtubule, Nuclear transfer

\footnotetext{
${ }^{1}$ All correspondence to: Naiara Zoccal Saraiva. Embrapa Amazônia Oriental, Trav. Dr. Enéas Pinheiro, s/no, Caixa Postal 48, CEP 66095-100, Belém, PA, Brazil. Tel: +55 913204 1113. e-mail: naiara.saraiva@embrapa.br

${ }^{2}$ Departamento de Medicina Veterinária Preventiva e Reprodução Animal, Universidade Estadual Paulista, Jaboticabal, Brazil.

${ }^{3}$ Embrapa Dairy Cattle, Valença, Brazil.

${ }^{4}$ Departamento de Medicina Veterinária, Faculdade de Zootecnia e Engenharia de Alimentos, Universidade de São Paulo, Pirassununga, Brazil.

${ }^{5}$ Centro APTA Bovinos de Corte, Instituto de Zootecnia, Sertãozinho, SP, Brazil.

${ }^{6}$ Embrapa Southeast Livestock, São Carlos, Brazil.
}

\section{Introduction}

Somatic cell nuclear transfer has been used extensively as a valuable tool for the production of animal clones from adult somatic cells and for the generation of transgenic animals for agricultural and biomedical research. However, the frequency of early postimplantation developmental arrest and abortion is high, especially in bovine (Hill et al., 2000). Biological and technical aspects related to somatic cell nuclear transfer may account for the limited success of the technique; oocyte enucleation is one of the crucial 
technical steps that need to be improved. Successful reprogramming of the donor nuclei depends on the sufficient supply of factors in the recipient oocyte. In this respect, any cytoplasmic alterations such as changes in nuclear maturation status, microtubule organization and microfilaments, or biochemical and physiological changes can potentially affect nuclear reprogramming and result in cloning failure ( $\mathrm{Li}$ et al., 2009).

The standard method of oocyte enucleation is time consuming, technically demanding, invasive and damaging to cytoplast spatial organization, including the loss of molecular factors that play a key role in subsequent oocyte activation, reprogramming of the transferred nucleus, mitotic spindle assembly, and early embryo development (Simerly et al., 2003; Miyara et al., 2006; Van Thuan et al., 2006). Furthermore, although nuclear DNA is removed during oocyte enucleation, there is the possibility of damage to mitochondrial DNA (Fischer-Russel et al., 2005). Therefore, simplification of this step is constantly a center of interest for scientists involved in the production of clones (Fulka et al., 2004).

Chemical enucleation using microtubuledepolymerizing drugs is an attractive procedure that has been used to simplify conventional enucleation methods. In chemically assisted enucleation (Yin et al., 2002a,b), metaphase II oocytes are exposed to an antimitotic drug and spindle depolymerization leads to the formation of a cortical protrusion on the surface of the oocyte that contains all oocyte chromosomes. This protrusion can be easily removed by micromanipulation techniques (Yin et al., 2002a) or by oocyte bisection (handmade cloning; Vajta et al., 2003). Anti-mitotic drugs have also been applied to pre-activated oocytes, resulting in the extrusion of a second polar body (PB) that contains all oocyte chromosomes. This technique is called chemically induced enucleation (IE).

In chemically IE, the treatment of pre-activated oocytes with high concentrations of demecolcine (0.4 to $0.5 \mu \mathrm{g} / \mathrm{ml})$, a microtubule-depolymerizing drug, has been proven to be effective for oocyte enucleation in mice (Baguisi \& Overström, 2000; Gasparrini et al., 2003; Ibáñez et al., 2003), goats (Ibáñez et al., 2002), and cattle (Fischer-Russel et al., 2005). Although mouse offspring were produced by nuclear transfer using this protocol (Baguisi \& Overström, 2000; Gasparrini et al., 2003), the percentage of embryos that developed to blastocyst stage was much lower among chemically enucleated nuclear transfer embryos than in those enucleated by conventional mechanical methods (Gasparrini et al., 2003).

To our knowledge, there has been to date only one report using chemically IE in cattle, and in which the authors employed intracytoplasmic injection for embryo reconstitution (Fischer-Russel et al., 2005). An understanding of the mechanism of chemically IE and modifications of the current protocol would lead to an increase in the frequency of induced enucleation and thus minimize the invasiveness of currently employed enucleation procedures. As further data are needed to fine tune the dose and duration of exposure to demecolcine in combination with modifications of the oocyte activation protocol (Fischer-Russel et al., 2005), the objective of the present study was to optimize the culture conditions of bovine oocytes exposed to demecolcine after oocyte activation in an attempt to improve the efficiency of chemically IE, and to evaluate tubulin and chromatin organization and the viability of cytoplasts produced by this technique.

\section{Material and methods}

\section{Chemicals}

Chemicals and media were purchased from Sigma Chemical Co. (St. Louis, MO, USA), unless otherwise stated.

\section{Experimental design}

Experiment I: Evaluation of different culture conditions with demecolcine for chemically induced enucleation

First, different experiments were conducted to standardize the chemically IE technique in bovine. Oocytes were treated with demecolcine at the beginning (Experiment Ia) or after the onset (Experiment $\mathrm{Ib}$ ) of the activation process.

Experiment Ia: Exposure to demecolcine at the beginning of parthenogenetic activation. Oocytes matured in vitro for $26 \mathrm{~h}$ were denuded and activated artificially with ionomycin $(5 \mu \mathrm{M}$ for $5 \mathrm{~min})$ and cycloheximide (10 $\mu \mathrm{g} / \mathrm{ml}$ for up to $5 \mathrm{~h}$ ). Three groups were established: (1) a control (not activated and not treated with demecolcine); (2) an activated (exposed only to the oocyte-activating agents); and (3) a treated group (DEME; exposed to the oocyte-activating agents and $0.05 \mu \mathrm{g} / \mathrm{ml}$ demecolcine). Treatment with demecolcine was initiated at the beginning of oocyte activation and samples were collected in quintuplicate from the three groups after 0,4 or $5 \mathrm{~h}$ of treatment. The oocytes were stained with $10 \mu \mathrm{g} / \mathrm{ml}$ Hoechst 33342 for $15 \mathrm{~min}$ and the percentage of metaphase II oocytes and activation and enucleation rates was determined under an epifluorescence microscope (330-385 nm).

Experiment Ib: Exposure to demecolcine after the onset of activation. After $26 \mathrm{~h}$ of in vitro maturation, oocytes were denuded and activated as described in Experiment Ia for up to $4 \mathrm{~h}$. Control, activated and demecolcine-treated (DEME) groups were also defined. However, in the DEME group the activation 
lasted for up to $4 \mathrm{~h}$ and treatment with $0.05 \mu \mathrm{g} / \mathrm{ml}$ demecolcine was started $0,0.5,1.0,1.5$, or $2.0 \mathrm{~h}$ after the onset of oocyte activation. Therefore, the following subgroups were established: (1) DEME 0-2 h (exposure to demecolcine between 0 and $2 \mathrm{~h}$ of activation); (2) DEME 0-4 h; (3) DEME 0.5-2.5 h; (4) DEME 0.5$4 \mathrm{~h}$; (5) DEME 1-3 h; (6) DEME 1-4 h; (7) DEME 1.5-3.5 h; (8) DEME 1.5-4 h, and (9) DEME 2-4 h. Quintuplicate samples were obtained. The oocytes were stained with $10 \mu \mathrm{g} / \mathrm{ml}$ Hoechst 33342 for $15 \mathrm{~min}$ and activation and enucleation rates were determined under an epifluorescence microscope (330-385 nm).

\section{Experiment II: Tubulin and chromatin organization in parthenogenetically activated oocytes submitted to chemically induced enucleation}

In the third experiment, we evaluated the effects of demecolcine on nuclear and microtubule organization of activated oocytes submitted to chemically IE. For this purpose, three groups were defined as described before (control, activated, and treated with demecolcine-DEME). In the DEME group, activated oocytes were exposed to the drug in the last $2 \mathrm{~h}$ of activation (DEME $2-4 \mathrm{~h}$ group). The samples were fixed and the configuration of chromatin and meiotic spindle (microtubules) was evaluated in triplicate at $0,0.5,1.0,2.0,2.5,3.0,4.0$, or $10 \mathrm{~h}$ after the onset of activation.

Experiment III: Early development of embryos reconstituted by nuclear transfer from chemically enucleated cytoplasts In the final experiment, after chemical or conventional enucleation, part of the cytoplasts were fixed in $4 \%$ paraformaldehyde for $1 \mathrm{~h}$ at room temperature and stored in phosphate-buffered saline (PBS) $+1 \%$ PVP for evaluation of the efficiency of enucleation by staining with Hoechst 33342 for 15 min and observation under an epifluorescence microscope (330-385 $\mathrm{nm})$. The remaining cytoplasts were reconstituted by nuclear transfer (NT) and presumptive zygotes were cultured in vitro. The rates of embryo development were determined after $48 \mathrm{~h}$ (cleavage) and on day 7 of culture (blastocysts).

\section{Oocyte recovery and in vitro maturation}

Bovine oocytes were obtained by follicular aspiration from ovaries obtained at a local slaughterhouse. The ovaries were transported to the laboratory in $0.9 \%$ saline solution at $30-35^{\circ} \mathrm{C}$. Follicles with diameters between 3 and $8 \mathrm{~mm}$ were aspirated using an 18-gauge needle attached to a 20-ml syringe and cumulus oocyte complexes (COCs) with at least three layers of cumulus cells and homogenous cytoplasm were selected. The COCs were washed in HEPES-buffered tissue culture medium-199 (TCM-199; Gibco BRL, Grand Island, NY,
USA) supplemented with $10 \%$ fetal calf serum (FCS), $0.20 \mathrm{mM}$ sodium pyruvate, and $83.4 \mu \mathrm{g} / \mathrm{ml}$ amikacin (Instituto Biochimico, Rio de Janeiro, Brazil). Groups of 15 COCs were matured in droplets $(100 \mu \mathrm{L})$ of TCM199 supplemented with 10\% FCS, $1.0 \mu \mathrm{g} / \mathrm{ml} \mathrm{FSH,} 50$ $\mu \mathrm{g} / \mathrm{ml}$ hCG (Profasi ${ }^{\mathrm{TM}}$, Serono, São Paulo, Brazil), 1.0 $\mu \mathrm{g} / \mathrm{ml}$ estradiol, $0.20 \mathrm{mM}$ sodium pyruvate, and 83.4 $\mu \mathrm{g} / \mathrm{ml}$ amikacin under mineral oil (Dow Corning Co., Midland, MI, USA) for up to $26 \mathrm{~h}$ at $38.5^{\circ} \mathrm{C}$ in an atmosphere of $5 \% \mathrm{CO}_{2}$ in air and maximum humidity.

\section{Isolation of nucleus donor cells}

Blastomeres were used as donor nucleus cells in the NT procedures. Cells were obtained from embryos produced in vitro with female and male sexed semen. The in vitro fertilization procedure was performed 24 $\mathrm{h}$ after in vitro maturation. For this purpose, groups of 15 oocytes were washed twice and transferred to $30 \mu l$ drops of TALP-IVF medium supplemented with $0.6 \%$ bovine serum albumin (BSA), $10 \mu \mathrm{g} / \mathrm{ml}$ heparin, $18 \mu \mathrm{M}$ penicillamine, $10 \mu \mathrm{M}$ hypotaurine and 1.8 $\mu \mathrm{M}$ epinephrine, and covered with sterile mineral oil. Frozen straws of semen from the same bull sexed by flow cytometry (Lagoa da Serra, Sertãozinho, Brazil) were used. Each straw containing approximately 2 million spermatozoa was centrifuged separately on a discontinuous 45/90 Percoll gradient for $7 \mathrm{~min}$ at 3600 $g$. The pellet was resuspended in $500 \mu \mathrm{l}$ TALP-IVF medium and again centrifuged for $5 \mathrm{~min}$ at $520 \mathrm{~g}$. After centrifugation, $100 \mu \mathrm{l}$ of the medium containing the pellet was collected from the bottom of the tube and homogenized in a conic tube. The final suspension was divided among 10 oocyte-containing drops, at a final concentration of approximately $10^{4}$ spermatozoa per oocyte. The plates were incubated for 18-20 h at $38.5^{\circ} \mathrm{C}$ in an atmosphere of $5 \% \mathrm{CO}_{2}$ under saturated humidity. After this period, embryos were cultured in synthetic oviductal fluid (SOF) supplemented with $2.5 \% \mathrm{FCS}$ and $5 \mathrm{mg} / \mathrm{ml} \mathrm{BSA}$ at $38.5^{\circ} \mathrm{C}$ in a humidified atmosphere of $5 \% \mathrm{CO}_{2}$ in air. Groups of 10-20 1-cell embryos were cultured in $100 \mu \mathrm{l}$ microdrops of culture medium for 5 days. The medium was renewed on the third day of embryo culture.

For the isolation of blastomeres used for reconstitution by NT from cytoplasts enucleated by the conventional technique, day- 5 embryos were cultured in SOF medium containing $0.4 \mu \mathrm{g} / \mathrm{ml}$ demecolcine for $12 \mathrm{~h}$ to synchronize cells in the metaphase stage. Approximately $3 \mathrm{~h}$ before the beginning of micromanipulation, the embryos were washed several times and cultured in demecolcine-free SOF medium so that at the time of use the cells were in $G_{1}$, a stage compatible with oocytes exhibiting high activity of maturation-promoting factor (MPF). For the chemical enucleation technique, in which activated oocytes 
(low MPF activity) are used, the embryos were not synchronized as about $80 \%$ of the cells are naturally in the S phase of the cell cycle (Campbell et al., 1996).

At the time of use, the zona pellucida was removed from the embryos by incubation in $0.5 \%$ pronase for 30 s. Next, the embryos were transferred to microdroplets of $\mathrm{Ca}^{2+}$ - and $\mathrm{Mg}^{2+}$-free PBS containing 0.3\% PVA and disaggregated into single blastomeres with a pipette. Blastomeres derived from early and compact morulae were used. The blastomeres were incubated for $30 \mathrm{~min}$ in $7.5 \mu \mathrm{g} / \mathrm{ml}$ cytochalasin B and then transferred to droplets for micromanipulation and used as donor nucleus cells.

\section{Nuclear transfer procedure}

\section{Oocyte enucleation techniques}

For conventional oocyte enucleation, oocytes matured in vitro for 18 to $20 \mathrm{~h}$ were used. After denuding with 2 $\mathrm{mg} / \mathrm{ml}$ hyaluronidase, the structures were incubated for $30 \mathrm{~min}$ at $38.5^{\circ} \mathrm{C}$ in SOF medium with HEPES buffer (HSOF) supplemented with 10\% FCS, 7.5 $\mu \mathrm{g} / \mathrm{ml}$ cytochalasin B, and $7.5 \mu \mathrm{g} / \mathrm{ml}$ Hoechst 33342 . Enucleation was performed under an inverted light microscope (Olympus IX-70), removing the first PB and part of the adjacent cytoplasm. Enucleation was confirmed by examining the oocyte under ultraviolet light to determine the absence of the metaphasic plate.

For chemically IE, oocytes matured in vitro for $26 \mathrm{~h}$ were denuded and activated artificially $(5 \mu \mathrm{M}$ ionomycin for $5 \mathrm{~min}$ and $10 \mu \mathrm{g} / \mathrm{ml}$ cycloheximide for $5 \mathrm{~h})$. After $1.5 \mathrm{~h}$ of activation, the oocytes were treated with demecolcine $(0.05 \mu \mathrm{g} / \mathrm{ml})$ for complete extrusion of the nuclear material of the oocyte together with the second PB. A the end of treatment, the second $\mathrm{PB}$ and a small part of the adjacent cytoplasm were removed by micromanipulation and the cytoplasts were subsequently used for NT.

\section{Embryo reconstitution}

Embryonic cells were individually transferred to the perivitelline space of each recipient cytoplast and cytoplast-cell complexes were electrofused in $0.3 \mathrm{M}$ mannitol solution containing $0.05 \mathrm{mM} \mathrm{CaCl}_{2}, 0.1 \mathrm{mM}$ $\mathrm{MgSO}_{4}$ and $0.1 \%$ PVA. Electrofusion was induced by a direct pulse of $1.5 \mathrm{kV} / \mathrm{cm}$ for $70 \mu \mathrm{s}$ (Bordignon et al., 1999) and successfully reconstituted structures were incubated in SOF $+10 \%$ FCS at $38.5^{\circ} \mathrm{C}$ in a humidified atmosphere of $5 \% \mathrm{CO}_{2}$ in air.

\section{Parthenogenetic activation}

Only reconstituted oocytes obtained by the conventional technique were activated at the end of the procedure, whereas in chemically IE oocytes were activated at the beginning of the protocol. The oocytes were chemically activated with $5 \mu \mathrm{M}$ ionomycin in
HSOF supplemented with $10 \%$ FCS for 5 min and with $10 \mu \mathrm{g} / \mathrm{ml}$ cycloheximide $+10 \mu \mathrm{g} / \mathrm{ml}$ cytochalasin B in SOF supplemented with $10 \%$ FCS for $5 \mathrm{~h}$ at $38.5^{\circ} \mathrm{C}$ in a humidified atmosphere of $5 \% \mathrm{CO}_{2}$ in air. Next, embryos were cultured until day 7 .

\section{Immunofluorescence analysis of tubulin and chromatin}

The protocol described by Liu et al. (1998) was used. Briefly, oocytes were incubated for $30 \mathrm{~min}$ in microtubule-stabilizing buffer (0.1 M PIPES, $\mathrm{pH}$ 6.9, $5 \mathrm{mM} \mathrm{MgCl} 2 \cdot 6 \mathrm{H}_{2} \mathrm{O}$ (Merck, Darmstadt, Germany), $2.5 \mathrm{mM}$ EGTA) containing 2\% formaldehyde, $0.1 \%$ Triton X-100, $1 \mu \mathrm{M}$ Taxol, $0.01 \%$ aprotinin, $1 \mathrm{mM}$ dithiothreitol, and 50\% deuterium oxide (Aldrich Chem. Co., Milwaukee, WI, USA). Next, oocytes were kept overnight at $4{ }^{\circ} \mathrm{C}$ in washing medium (WM; PBS with $0.02 \% \mathrm{NaN}_{3}, 0.01 \%$ Triton $\mathrm{X}-100,0.2 \%$ non-fat dry milk, 2\% FCS, 2\% BSA, and $0.1 \mathrm{M}$ glycine) and were then incubated in WM containing anti- $\alpha$-tubulin mouse monoclonal antibody (1:50) conjugated with fluorescein isothiocyanate (FITC) for $2 \mathrm{~h}$ at $38^{\circ} \mathrm{C}$. After washing in WM, oocytes were stained with $10 \mu \mathrm{g} / \mathrm{ml}$ Hoechst 33342 in WM for $10 \mathrm{~min}$, mounted on slides with $90 \%$ glycerol in PBS, and examined under an epifluorescence microscope at 330-385 and 420-490 $\mathrm{nm}$. For the evaluation of nuclear kinetics, the oocytes were classified as immature, metaphase II (MII) or activated (AII/TII with extrusion of the 2nd PB or pronucleus stage) (Fig. 1). In addition, the oocytes were classified according to microtubule organization (present, reduced, or absent) as described in Fig. 2.

\section{Statistical analysis}

The rates of activation, enucleation and embryo development were analyzed by chi-squared $\left(\chi^{2}\right)$ test or Fisher's exact test, when appropriate. The percentages obtained in Experiment II were submitted to analysis of variance (ANOVA) and means were compared by the Tukey test. All analyses were performed using Statistical Analysis System (SAS) 9.1 software, adopting a level of significance of $5 \%$.

\section{Results}

\section{Addition of demecolcine at the beginning of parthenogenetic activation}

At the beginning of assessment $(0 \mathrm{~h})$, most oocytes were at the MII stage $(133 / 163,81.6 \%)$. A significant increase in the percentage of oocytes with extrusion of the second $\mathrm{PB}$ was observed in the groups activated for 4 or $5 \mathrm{~h}$. These groups did not differ from one another 
Table 1 Percentage of metaphase II (MII), activated, and enucleated (EN) oocytes in the control group (CON), group activated with $5 \mu \mathrm{M}$ ionomycin for $5 \mathrm{~min}$ and $10 \mu \mathrm{g} / \mathrm{ml}$ cycloheximide (ACTIV), and group activated and treated with $0.05 \mu \mathrm{g} / \mathrm{ml}$ demecolcine (DEME) for 0,4 and $5 \mathrm{~h}$

\begin{tabular}{llcccc}
\hline Time $(\mathrm{h})$ & Treatments & MII $(\%)$ & Activated $(\%)$ & EN $(\%)$ & Total \\
\hline 0 & - & $133(81.6)^{a}$ & $02(1.3)^{c}$ & $01(0.6)^{c}$ & 163 \\
4 & CON & $121(80.7)^{a}$ & $04(2.7)^{c}$ & $0^{c}$ & 150 \\
& ACTIV & $31(19.6)^{b}$ & $97(61.4)^{a}$ & $07(4.4)^{b}$ & 158 \\
5 & DEME & $26(17.7)^{b}$ & $53(36.0)^{b}$ & $58(39.4)^{a}$ & 147 \\
& CON & $126(79.2)^{a}$ & $05(3.1)^{c}$ & $0^{c}$ & 159 \\
& ACTIV & $34(21.6)^{b}$ & $100(63.7)^{a}$ & $13(8.3)^{b}$ & 157 \\
& DEME & $29(18.9)^{b}$ & $47(30.7)^{b}$ & $64(41.8)^{a}$ & 153 \\
\hline
\end{tabular}

$\overrightarrow{a, b, c}$ Values with different superscript letters within the same column differ $(P<0.05$, chi-squared test).
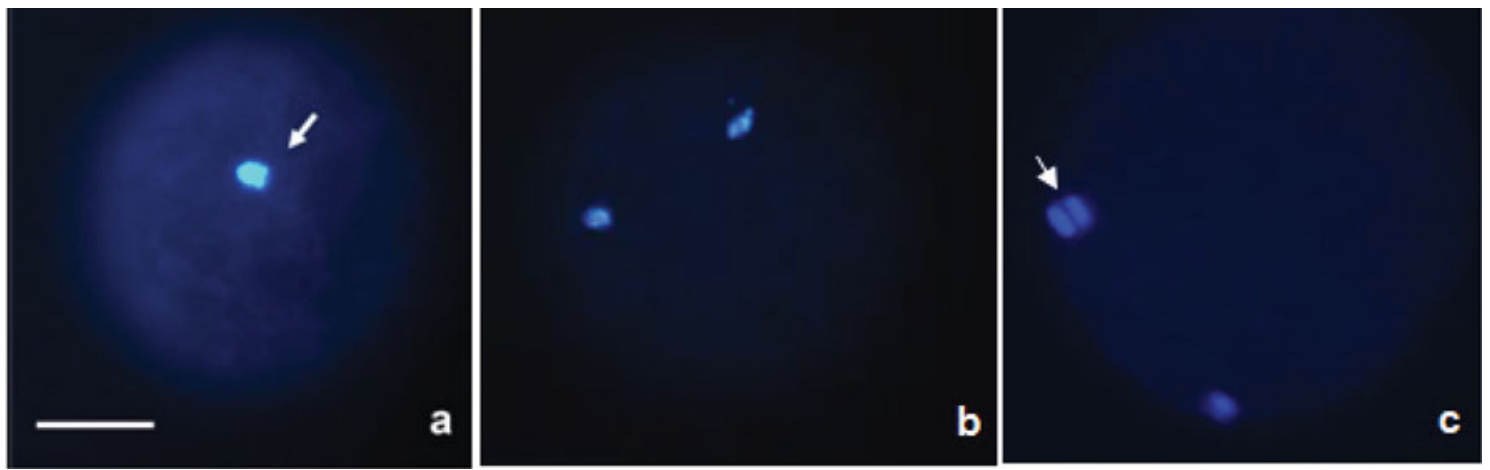

Figure 1 Evaluation of nuclear kinetics. Photomicrographs of activated bovine oocytes treated with demecolcine. Categories of oocytes observed: $(a)$ metaphase I (MI) oocyte; $(b)$ metaphase II (MII) oocyte; $(c)$ anaphase/telophase II (AII/TII) oocyte. Oocytes were stained with Hoechst 33342 and observed under an epifluorescence microscope. The arrows indicate nuclear material (blue). Bar $=50 \mu \mathrm{m}$.
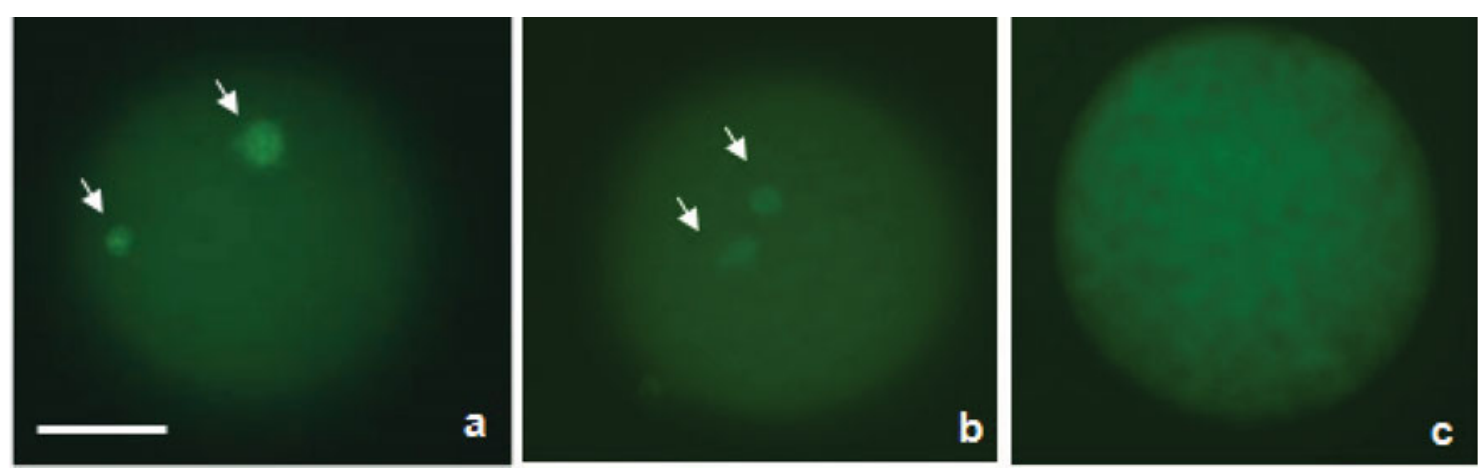

Figure 2 Evaluation of microtubule configuration. Photomicrographs of activated bovine oocytes treated with demecolcine. Categories of oocytes observed: (a) oocyte with microtubules (MTs); (b) oocyte with reduced MTs; (c) oocyte without MTs. Oocytes were stained with FITC-conjugated anti- $\alpha$ tubulin antibody (1:50) and observed under an epifluorescence microscope. The arrows indicate MTs (green). Bar $=50 \mu \mathrm{m}$.

and the percentage of oocytes was higher than in the groups treated with demecolcine (Table 1).

Enucleation rates were higher in the DEME group $(P<0.05)$ than in the control and activated groups after 4 and $5 \mathrm{~h}$ of activation (Table 1), which also differed from one another. However, demecolcine probably interfered with oocyte activation, resulting in low enucleation rates (39.4-41.8\%). No significant difference was observed between groups treated with demecolcine for 4 and $5 \mathrm{~h}$ (Table 1 ).

\section{Addition of demecolcine after the onset of parthenogenetic activation}

Demecolcine exerted no damaging effects on oocyte activation when added to the medium $1.5 \mathrm{~h}$ after 
Table 2 Percentage of activated oocytes after incubation in medium containing $5 \mu \mathrm{M}$ ionomycin for $5 \mathrm{~min}$ and $10 \mu \mathrm{g} /$ $\mathrm{ml}$ cycloheximide for $4 \mathrm{~h}$ and different times of treatment with demecolcine: DEME 0-2 h (exposure to demecolcine between 0 and $2 \mathrm{~h}$ of activation); DEME 0-4 h; DEME 0.52.5 h; DEME 0.5-4 h; DEME 1-3 h; DEME 1-4 h; DEME 1.5-3.5 h; DEME 1.5-4 h; DEME 2-4 h

\begin{tabular}{lll}
\hline Treatments & Activated (\%) & Total \\
\hline CON & $01(0.9)^{*}$ & 114 \\
ACTIV & $97(74.6)^{a, b}$ & 130 \\
DEME 0-2 h & $42(38.9)^{*}$ & 108 \\
DEME 0-4 h & $36(32.7)^{*}$ & 110 \\
DEME 0.5-2.5 h & $59(54.1)^{*}$ & 109 \\
DEME 0.5-4 h & $56(48.7)^{*}$ & 115 \\
DEME 1-3 h & $69(59.0)^{*}$ & 117 \\
DEME 1-4 h & $62(55.8)^{*}$ & 111 \\
DEME 1.5-3.5 h & $64(62.7)^{a}$ & 102 \\
DEME 1.5-4 h & $76(69.7)^{a, b}$ & 109 \\
DEME 2-4 h & $87(77.0)^{b}$ & 113 \\
\hline
\end{tabular}

*The asterisk indicates difference in relation to activated group.

${ }_{a, b}$ Values followed by the same letter between rows did not differ significantly $(P>0.05$, chi-squared test).

ACTIV: activated group; CON: control group.

the beginning of the process, with no significant differences $(P>0.05)$ between the DEME 1.5-3.5 $\mathrm{h}$, DEME 1.5-4 h or DEME 2-4 h groups and the group submitted to activation only (mean of $62.7-77.0 \%$ ) (Table 2).

Enucleation rates differed significantly between all groups treated with demecolcine and the control $(0 / 114)$ and activated (0/130) groups (Fig. 3). The DEME $1.5-4 \mathrm{~h}(42.2 \%)$ and DEME $2-4 \mathrm{~h}(54.0 \%)$ groups presented higher enucleation rates $(P<0.05)$ than all other groups (26.8-36.3\%), but there was no difference between these two groups. As the percentage of activated and enucleated oocytes was higher in the DEME 2-4 h group, this treatment was chosen for the following experiments.

\section{Evaluation of nuclear and microtubule kinetics in pre-activated oocytes treated with demecolcine}

The frequency of immature oocytes was similar in the three groups (control, activated and DEME) throughout the period of evaluation (Fig. 4). Effects of activation were detected after $2 \mathrm{~h}$, when the mean percentage of activated oocytes was higher in the activated and DEME groups in comparison to the control group (Fig. 4).

The percentage of oocytes with microtubules was significantly reduced $(P<0.05)$ in the DEME group when compared with the activated group $2.5 \mathrm{~h}$ after the onset of activation ( $0.5 \mathrm{~h}$ of exposure to demecolcine). After $10 \mathrm{~h}$, lower mean percentages of oocytes with microtubules were observed in the activated and DEME groups compared to control and this percentage also differed between the first two groups (Fig. 5). In parallel, there was a significant increase $(P<0.05)$ of oocytes with reduced microtubules in the DEME group $2.5 \mathrm{~h}$ after the onset of activation. This higher mean percentage was observed up to $4 \mathrm{~h}$ after the onset of activation when compared to the control and activated groups (Fig. 5).

Microtubule reduction was observed in approximately $50 \%$ of oocytes of the DEME group $10 \mathrm{~h}$ after the onset of activation. However, no significant difference was observed between the treated and activated groups, only when compared with the control group. In addition, $23 \%$ of oocytes displayed absent microtubules in the DEME group, a mean value higher than that observed in the control and activated groups $(P<0.05)$ (Fig. 5).

\section{Early development of embryos reconstituted by nuclear transfer from cytoplasts produced by chemically induced enucleation}

In relation to cleavage and blastocyst rates, no significant differences were observed between groups $(P>0.05)$ despite a tendency towards lower embryo production in the chemically enucleated group. As no significant difference was observed between sexes, the results of female and male embryos were pooled for each technique (Table 3).

\section{Discussion}

First, oocytes were exposed to demecolcine at the start of activation. However, as the enucleation rates were relatively low (39.45-42.38\%), a second experiment was conducted in which demecolcine was added after the onset of oocyte activation and higher enucleation rates were obtained. No damaging effect of demecolcine on oocyte activation was observed when treatment was started $1.5 \mathrm{~h}$ after the exposure of oocytes to the activating agents, with a mean enucleation rate of $54 \%$. Similar findings have been reported by Ibáñez et al. (2003) and Fischer-Russel et al. (2005) for mouse and bovine oocytes, respectively, and can be explained by the fact that demecolcine impairs spindle rotation in activated oocytes, an event that normally precedes formation of the PB. Thus, the beginning of demecolcine treatment in relation to oocyte activation is the key point for successful enucleation. The present results agree with previous studies showing that an intact spindle is required for the degradation of cyclin $\mathrm{B}$ and the consequent inactivation of MPF and exit from the M phase (Kubiak et al., 1993). 
Table 3 Number and percentage of cleaved embryos and blastocysts produced by nuclear transfer from donor embryo cells after conventional or chemically induced enucleation in bovine

\begin{tabular}{lccc}
\hline Treatments & No. fused & No. cleaved (\%) & No. blastocyst (\%) \\
\hline Conventional & 66 & $42(63.6)$ & $16(24.2)$ \\
Chemical-induced & 90 & $63(70.0)$ & $14(15.5)$ \\
\hline
\end{tabular}

No significant differences were observed between groups $(P>0.05$, chi-squared test).

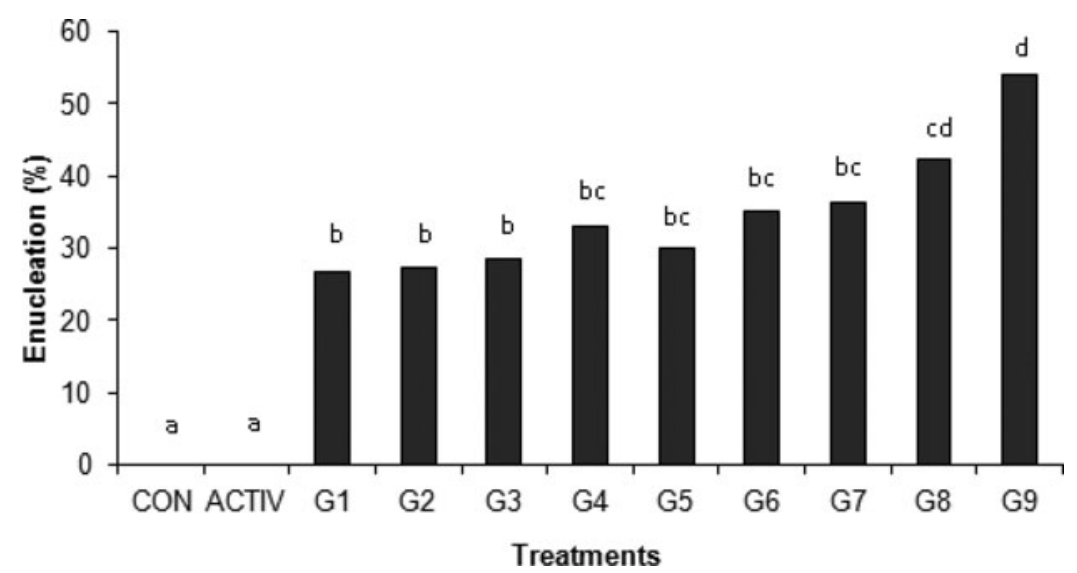

Figure 3 Graphic representation of the percentage of enucleated oocytes (EN) after activation with $5 \mu \mathrm{M}$ ionomycin for 5 min and $10 \mu \mathrm{g} / \mathrm{ml}$ cycloheximide for up to $4 \mathrm{~h}$ and different treatments with demecolcine: group 1 (DEME 0-2 h); group 2 (DEME 0-4 h); group 3 (DEME 0.5-2.5 h); group 4 (DEME 0.5-4 h); group 5 (DEME 1-3 h); group 6 (DEME 1-4 h); group 7 (DEME 1.5-3.5 h); group 8 (DEME 1.5-4 h); group 9 (DEME $2-4 \mathrm{~h}$ ). ${ }^{\mathrm{a}-\mathrm{d}}$ Columns followed by different superscript letters differ from one another $(P<0.05$, chi-squared test). ACTIV: activated group; CON: control group.

The enucleation rates obtained in the present study were lower than those reported by Fischer-Russel et al. (2005) for activated bovine oocytes treated with demecolcine (up to $91.7 \%$ ). However, the high rates reported by these authors were obtained $5 \mathrm{~h}$ after the onset of oocyte activation. A new assessment performed $17 \mathrm{~h}$ after the onset of activation showed a decline in enucleation, with rates ranging from 3.4$46.1 \%$. These findings indicate that the chromosomes were reintegrated into the oocyte after incomplete extrusion of the second $\mathrm{PB}$, demonstrating the inefficiency of the enucleation process in the absence of micromanipulation of these structures.

In this study, several oocytes contained subcortical nuclear material which was connected to the chromosomes present in the PB by a spindle remnant, a feature also observed in activated mouse oocytes (Ibáñez et al., 2003). These oocytes were considered to be non-enucleated. Incomplete release of the PB may have occurred in these treated oocytes as a consequence of the lack of intact microtubules for the formation of contractile rings, which are responsible for cytokinesis (Larkin \& Danilchik, 1999). However, since this material is juxtaposed to the $\mathrm{PB}$, the latter can be easily removed by micromanipulation, facilitating the enucleation procedure and promoting an increase of oocyte enucleation rates. In addition, we found that exposure to demecolcine can be interrupted after 1 $\mathrm{h}$ of treatment, contributing to the optimization of the current protocol, which recommends treatment for $2 \mathrm{~h}$ (Fischer-Russel et al., 2005), reducing the time of exposure to the drug.

After optimization of the chemical enucleation protocol, we analyzed chromatin and microtubule kinetics in these activated oocytes treated with demecolcine. Previously our group observed that in MII bovine oocytes, the microtubule-depolymerizing action of demecolcine occurred after only $0.5 \mathrm{~h}$ of treatment, with the complete absence of these structures in most of the oocytes analyzed (Saraiva et al., 2009). Different results were obtained in the present study for pre-activated oocytes. Although the density of microtubules was reduced in these oocytes, complete disappearance of these structures was not seen in most of them. Similar results have been reported for mouse oocytes in which microtubules also had not disappeared completely even after $2 \mathrm{~h}$ of treatment with demecolcine (Ibáñez et al., 2003).

The rapid effect of demecolcine on metaphase II oocytes (Saraiva et al., 2009), in which microtubules disappeared completely within $0.5 \mathrm{~h}$ of treatment, is likely to reflect differences in the sensitivity of the 
A

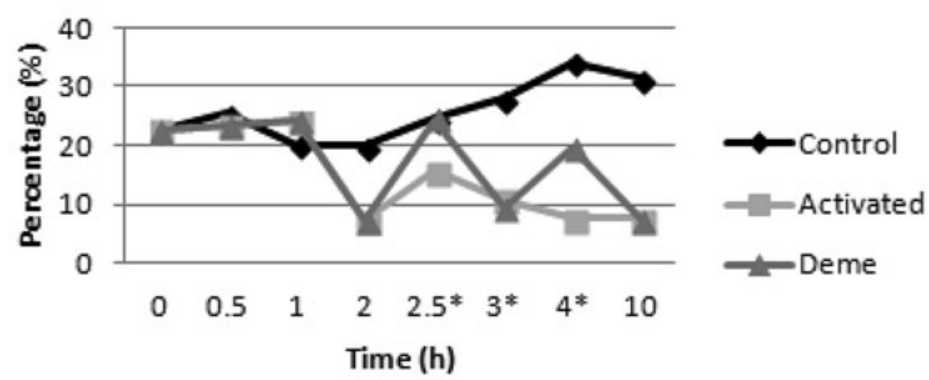

B

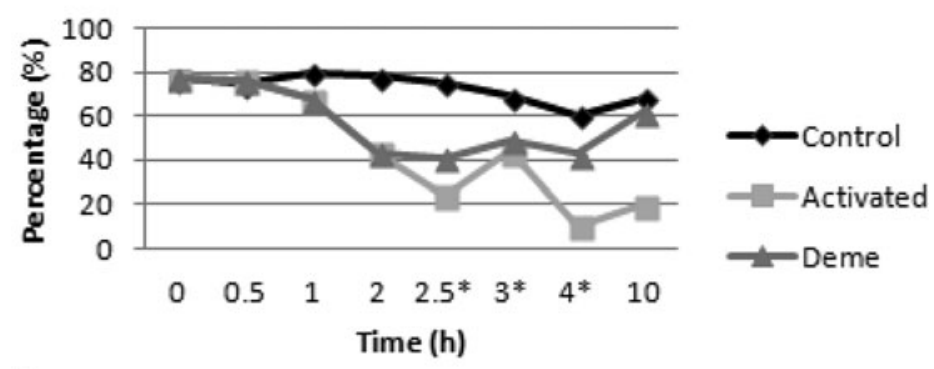

C

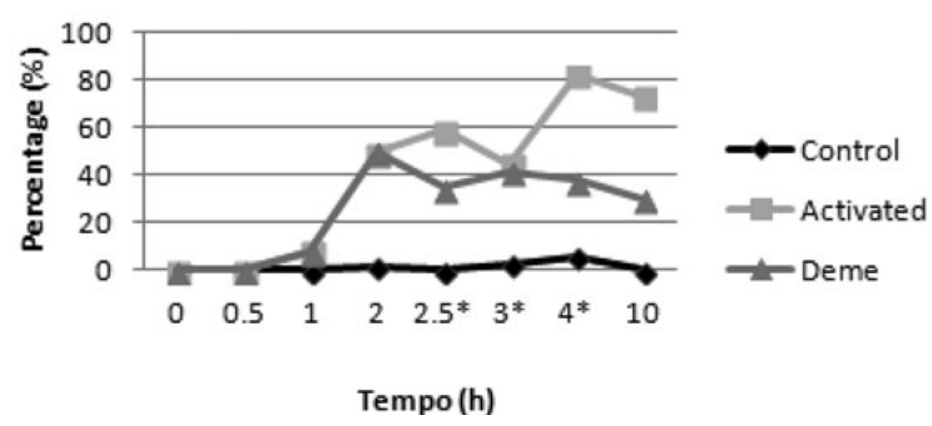

Figure 4 Graphic representation of nuclear kinetics in activated bovine oocytes treated with demecolcine and evaluated at intervals of 0.5 and $1.0 \mathrm{~h}$ between 0 and $10 \mathrm{~h}$ after the onset of activation. Control (not activated or treated with demecolcine); Activated (exposed only to the oocyte-activating agents); DEME (activated and treated with demecolcine for $2 \mathrm{~h}$ ). ( $A$ ) Immature oocytes; $(B)$ mature oocytes; $(C)$ activated oocytes. The asterisk indicates exposure to demecolcine.

meiotic spindle of these structures, with the spindle of metaphase II oocytes being a more sensitive target for demecolcine than the spindle of activated oocytes. The presence of these spindle remnants may indicate differences in the stability of some microtubules in the spindle, which probably correspond to interpolar microtubules (Combelles \& Albertini, 2001).

In the present study, reduction of microtubules was observed in approximately $50 \%$ of treated oocytes at the end of assessment and complete disappearance of these structures in $23 \%$, with visible microtubules being seen in only $27 \%$ of oocytes. These findings indicate the absence of immediate repolymerization of microtubules after culture of pre-activated oocytes in demecolcine-free medium, in contrast to metaphase II oocytes, as evaluated previously by our group (Saraiva et al., 2009). This fact may have some negative consequences for subsequent embryonic development as microtubules are important during the first cleavages. However, a reduction of microtubule density was also observed in oocytes of activated group $10 \mathrm{~h}$ after the onset of the process, suggesting that this reduction is a 'physiological' process.

It is important that future research also assesses the behaviour of microfilaments during treatment with demecolcine, especially in cases of pre-activated oocytes. Demecolcine-induced enucleation requires the artificial activation of the oocyte prior to its exposure to the microtubule-destabilizing drug. Parthenogenetic activation of bovine oocytes can be achieved by using compounds that increase intracellular calcium, such as ionomycin (calcium ionophore), followed by treatment for several hours with the protein synthesis inhibitor $\mathrm{CHX}$, which induces the resumption of meiosis by 
A

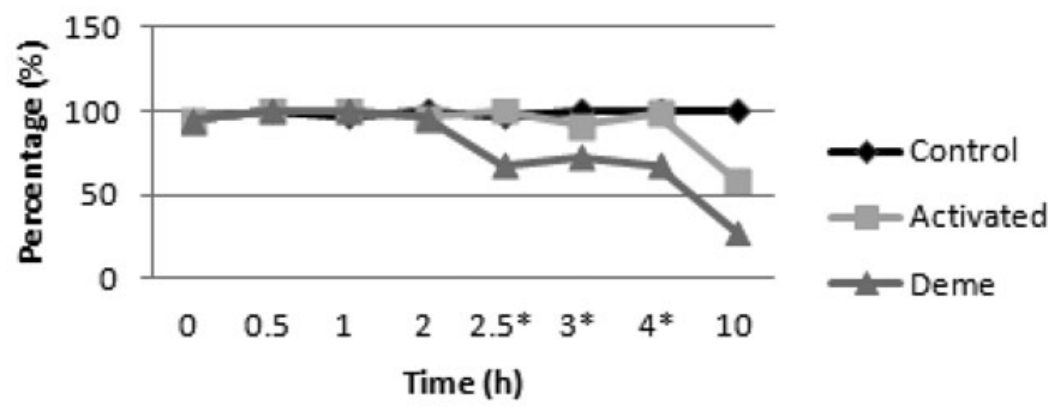

B

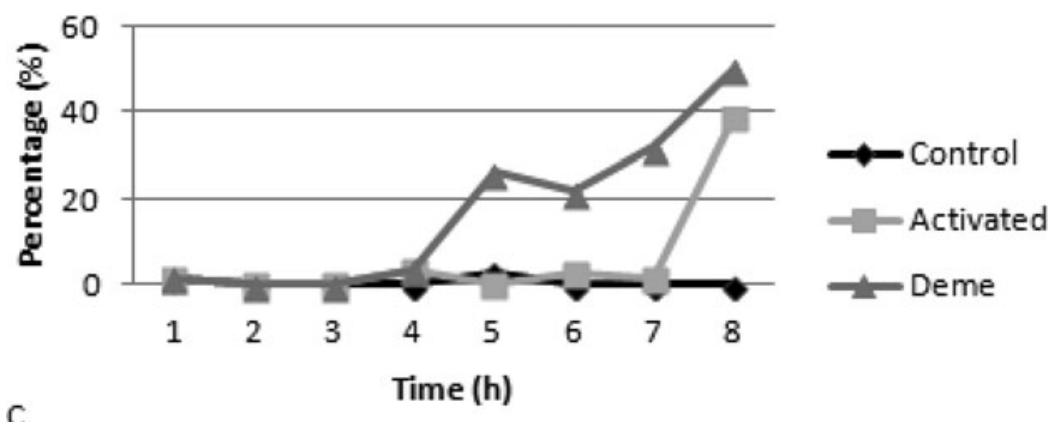

C

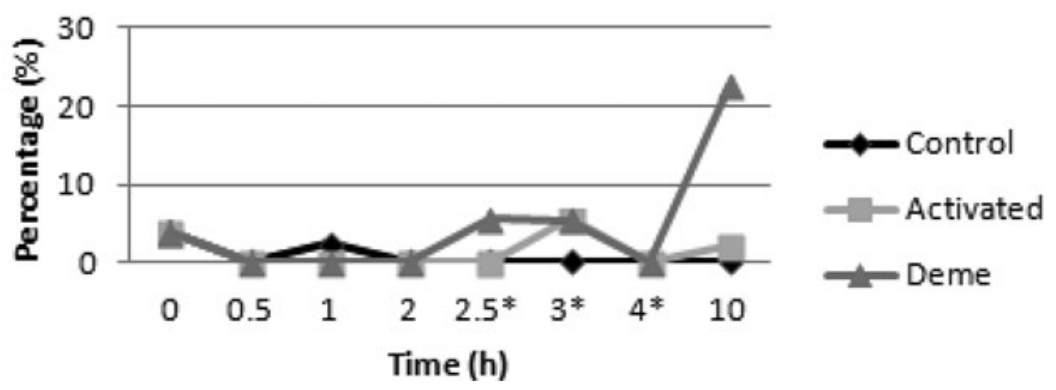

Figure 5 Graphic representation of microtubule kinetics in activated bovine oocytes treated with demecolcine and evaluated at intervals of 0.5 and $1.0 \mathrm{~h}$ between 0 and $10 \mathrm{~h}$ after the onset of activation. Control (not activated or treated with demecolcine); Activated (exposed only to the oocyte-activating agents); DEME (activated and treated with demecolcine for $2 \mathrm{~h}$ ). ( $A$ ) oocytes with microtubules; $(B)$ oocytes with reduced microtubules; $(C)$ oocytes without microtubules. The asterisk indicates exposure to demecolcine.

inactivation of MPF and mitogen-activated protein kinase (MAPK) (Fischer-Russel et al., 2005). Recently, Vasilev et al. (2012) observed that artificial elevation of intracellular $\mathrm{Ca}^{2+}$ levels with ionomycin immediately led to drastic alteration of the actin cytoskeleton in the immature oocytes, which exhibited depolymerization of the actin meshwork in the subplasmalemmal regions along with highly enhanced polymerization and bundling of the actin filaments in the inner cytoplasm.

As demonstrated in the sea urchin, zygote cell cleavage depends heavily on the regulation of the actin cytoskeleton (Dales \& De Santis, 1981). Hence, actin is intimately implicated in fertilization and in the early stages of development. These alterations led to difficulties in cell cleavage in the monospermic zygotes and eventually to a higher rate of abnormal development. Then, further studies are needed to better characterize the mechanism of demecolcine-induced enucleation of preactivated oocytes, considering the involvement of microfilaments on the subsequent embryonic development. In this context, Meng et al. (2011) observed that in bovine MII oocytes, the microtubules were concentrated to form the normal spindle structure with microfilaments distributed uniformly in the cytoplasm, while in the demecolcinetreated oocytes, the spindle microtubules were nearly depleted by demecolcine, but the microfilaments were hardly affected. The demecolcine treatment seemed to have altered the balance between the 
interaction of microtubules and microfilaments in the treated oocytes, which appears to be the result of the cytoplasmic protrusion. Without the aid of the microtubules, the chromosomes were compressed by the microfilaments to form a protrusion on the oocyte membrane.

Evaluation of embryonic development showed cleavage rates ranging from $63.6-70.0 \%$ in the groups reconstituted by the different techniques. Blastocyst rates ranged from 15.5-24.2\%. Although embryo production tended to be lower for oocytes obtained by chemically IE, no significant differences were observed when compared with the conventional procedure.

There are various factors that justify the use of demecolcine for NT. According to Simerly et al. (2003, 2004), removal of the meiotic spindle during conventional enucleation seems to be responsible for the low development of embryos reconstituted from somatic cells in primates, since the centrosome and some motor proteins, such as NuMA and KIFC1, which are fundamental for the formation of the spindle poles during mitosis, are depleted from the ooplasm, resulting in spindle dysfunction and aneuploid embryos. In addition, traditional mechanical enucleation has been shown to reduce the amount of spindleassociated $\gamma$-tubulin in mouse oocytes (Van Thuan et al., 2006). Within this context, alternative methods of oocyte enucleation may permit the preservation of spindle-associated factors in enucleated oocytes and consequently improve embryo quality.

Cloned mammalian species have been produced from either demecolcine-assisted (Yin et al., 2002a; Kawakami et al., 2003; Vajta et al., 2003; Tani et al., 2006) or demecolcine-induced enucleated oocytes (Baguisi \& Overström, 2000; Gasparrini et al., 2003) reconstituted with somatic or embryonic stem cells. The only report of demecolcine-induced enucleation in bovine (Fischer-Russel et al., 2005) showed that intracytoplasmic injection of the donor nucleus prior to oocyte activation and treatment with demecolcine or after 1.5 and $2.0 \mathrm{~h}$ post-activation yielded 19 and $15.7 \%$ of blastocysts, respectively. For both treatments, cleavage and blastocyst rates were similar to those observed for the control group (26.1\%). These data agree with the present results, indicating that demecolcineinduced enucleation does not compromise embryo development in cattle.

In summary, we optimized the chemically IE protocol and showed that the procedure may be shortened. However, demecolcine impaired meiotic progression when it was added to the medium during the onset of the activation process. Furthermore, demecolcine reduced microtubule density in preactivated oocytes, but these structures did not disappear completely in most oocytes, and apparently there was no immediate repolymerization of micro- tubules after culture in demecolcine-free medium. Nevertheless, the chemically IE technique permitted to obtain viable cytoplasts for NT, providing results similar to those observed for the conventional method. Studies evaluating the ability to establish pregnancy and to produce live offspring are needed to confirm the use of demecolcine-induced enucleation in bovine.

\section{Acknowledgements}

This study was supported by the São Paulo Research Foundation (FAPESP), Brazil.

\section{References}

Baguisi, A. \& Overström, E.W. (2000). Induced enucleation in nuclear transfer procedures to produce cloned animals. Theriogenology 53, 209.

Bordignon, V., Clarke, H.J. \& Smith, L.C. (1999). Developmentally regulated loss and reappearance of immunoreactive somatic histone $\mathrm{H} 1$ on chromatin of bovine morulastage nuclei following transplantation into oocytes. Biol. Reprod. 61, 22-30.

Campbell, K.H.S., Loi, P., Otaegui, P.J. \& Wilmut, I. (1996). Cell cycle co-ordination in embryo cloning by nuclear transfer. Rev. Reprod. 1, 40-6.

Combelles, C.M. \& Albertini, D.F. (2001). Microtubule patterning during meiotic maturation in mouse oocytes is determined by cell cycle-specific sorting and redistribution of $\gamma$-tubulin. Dev. Biol. 239, 281-94.

Dales, B. \& De Santis, A. (1981). The effect of cytochalasin B and D on the fertilization of sea urchins. Dev. Biol. 83, 2327.

Fischer-Russel, D.F., Ibáñez, E., Albertini, D.F. \& Overstrom, E.W. (2005). Activated bovine cytoplasts prepared by demecolcine-induced enucleation support development of nuclear transfer embryos in vitro. Mol. Reprod. Dev. 72, 161-70.

Fulka, J., Loi, P., Fulka, H., Ptak, G. \& Nagai, T. (2004). Nucleus transfer in mammals: noninvasive approaches for the preparation of cytoplasts. Trends Biotechnol. 22, 279-83.

Gasparrini, B., Gao, S., Ainslie, A., Fletcher, J., Mc Garry, M., Rithie, W.A., Springbett, A.J., Overström, E.W., Wilmut, I. \& de Sousa, P.A. (2003). Cloned mice derived from embryonic stem cell karyoplasts and activated cytoplasts prepared by induced enucleation. Biol. Reprod. 68, 1259-66.

Hill, J. R., Burghardt, R.C., Jones, K., Long, C.R., Looney, C. R., Shin, T., Spencer, T. E., Thompson, J.A., Winger, Q.A. \& Westhusin, M.E. (2000). Evidence for placental abnormality as the major cause of mortality in first trimester somatic cell cloned bovine fetuses. Biol. Reprod. 63, 1787-94.

Ibáñez, E., Sanfins, A., Combelles, C., Albertini, D.F. \& Overström, E.W. (2002). Induced enucleation of mouse and goat oocytes: kinetic and phenotypic characterizations. Theriogenology 57, 421.

Ibáñez, E., Albertini, D.F. \& Overström, E.W. (2003). Demecolcine-induced oocyte enucleation for somatic cell cloning: coordination between cell-cycle egress, kinetics of 
cortical cytoskeletal interactions, and second polar body extrusion. Biol. Reprod. 68, 1249-58.

Kawakami, M., Tani, T., Yabuuchi, A., Kobayashi, T., Murakami, H., Fujimura, T., Kato, Y. \& Tsunoda, Y. (2003). Effect of demecolcine and nocodazole on the efficiency of chemically assisted removal of chromosomes and the developmental potential of nuclear transferred porcine oocytes. Cloning Stem Cells 5, 379-87.

Kubiak, J.Z., Weber, M., De Pennart, H., Winston, J. \& Maro, B. (1993). The metaphase II arrest in mouse oocytes is controlled through microtubule-dependent destruction of cyclin B in the presence of CSF. EMBO J. 12, 3773-8.

Larkin, K. \& Danilchik, M.V. (1999). Microtubules are required for completion of cytokinesis in sea urchin eggs. Dev. Biol. 214, 215-26.

Li, G-P., White, K.L., Aston, K.I., Bunch, T.D., Hicks, B., Liu, Y. \& Sessions, B.R. (2009). Colcemid-treatment of heifer oocytes enhances nuclear transfer embryonic development, establishment of pregnancy and development to term. Mol. Reprod. Dev. 76, 620-8.

Liu, L., Ju, J-C. \& Yang, X. (1998). Differential inactivation of maturation-promoting factor and mitogen-activated protein kinase following parthenogenetic activation of bovine oocytes. Biol. Reprod. 59, 537-45.

Meng, Q., Wu, X., Bunch, D., White, K., Sessions, B. R., Davies, C. J., Rickords, L. \& Li, G-P. (2011). Enucleation of demecolcine-treated bovine oocytes in cytochalasinfree medium: mechanism investigation and practical improvement. Cell. Reprogram. 13, 411-8.

Miyara, F., Han, Z., Gao, S., Vassena, R. \& Latham, K.E. (2006). Non-equivalence of embryonic and somatic cell nuclei affecting spindle composition in clones. Dev. Biol. 289, 206-17.

Saraiva, N.Z., Perecin, F., Méo, S.C., Ferreira, C.R., Tetzner, T.A.D. \& Garcia, J.M. (2009). Demecolcine effects on microtubule kinetics and on chemically assisted enucleation of bovine oocytes. Cloning Stem Cells 11, 141-51.
Simerly, C., Dominko, T., Navara, C., Payne, C., Capuano, S., Gosman, G., Chong, K.Y., Takahashi, D., Chace, C., Compton, D., Hewitson, L. \& Schatten, G. (2003). Molecular correlates of primate nuclear transfer failures. Science 300, 297.

Simerly, C., Navara, C., Hyun, S.H., Lee, B.C., Kang, S.K., Capuano, S., Gosman, G., Dominko, T., Chong, K.Y., Compton, D., Hwang, W.S. \& Schatten, G. (2004). Embryogenesis and blastocyst development after somatic cell nuclear transfer in nonhuman primates: overcoming defects caused by meiotic spindle extraction. Dev. Biol. 276, 237-52.

Tani, T., Shimada, H., Kato, Y. \& Tsunoda, Y. (2006). Demecolcine-assisted enucleation for bovine cloning. Cloning Stem Cells 8, 61-6.

Vajta, G., Lewis, I.M., Trounson, A.O., Purup, S., MaddoxHyttel, P., Schmidt, M., Pedersen, H.G., Greve, T. \& Callesen, H. (2003). Handmade somatic cell cloning in cattle: analysis of factors contributing to high efficiency in vitro. Biol. Reprod. 68, 571-8.

Van Thuan, N., Wakayama, S., Kishigami, S. \& Wakayama, T. (2006). Donor centrosome regulation of initial spindle formation in mouse somatic cell nuclear transfer: roles of gamma-tubulin and nuclear mitotic apparatus protein 1. Biol. Reprod. 74, 777-87.

Vasilev, F., Chun, J. T., Gragnaniello, G., Garante, E. \& Santella, L. (2012). Effects of ionomycin on egg activation and early development in starfish. PLoS One 7, e39231.

Yin, X.J., Kato, Y. \& Tsunoda, Y. (2002a). Effect of enucleation procedures and maturation conditions on the development of nuclear-transferred rabbit oocytes receiving male fibroblast cells. Reproduction 124, 41-7.

Yin, X.J., Tani, T., Yonemura, I., Kawakami, M., Miyamoto, K., Hasegawa, R., Kato, Y. \& Tsunoda, Y. (2002b). Production of cloned pigs from adult somatic cells by chemically assisted removal of maternal chromosomes. Biol. Reprod. $67,442-6$. 